\title{
Means for the mechanic agricultural equipment modernization forecasting
}

\author{
Andrey Chistyakov ${ }^{1}$, and Olga Babenko ${ }^{1, *}$ \\ ${ }^{1}$ Don State Technical University, 1, Gagarin Sq., 344003, Rostov-on-Don, Russia
}

\begin{abstract}
The article presents a model for assessing the effectiveness of the tool for forecasting the timing and direction of the product (product) modernization. The authors gave a justification for the developed model, derived formulas that help determine the timing of modernization, the intensity of allocating resources for it, and make a justified choice of the direction of this modernization.
\end{abstract}

\section{Introduction}

Any market supply is a very responsible decision for an organization, often affecting not only its efficiency, but in case of the gross miscalculations, questioning the existence of the entire business.

The modern paradigm of the portfolio policy (sometimes called the paradigm of " planned obsolescence ") differs from the previous, traditional one in its almost parallel development of a traditional product, its modernizations and modifications, as well as the parallel development of a product to replace it. In addition to the paradigm of "planned obsolescence" the portfolio policy is characterized by the variety of the market supply forms, elaborated on the basis of the produced goods. The structure of the organization's market supply and its turnover stages are determined by the conjuncture of the goods attractiveness on the market.

In this research article, the term "market supply" means a continuum starting with the product supply by a producer, while the product itself possess a set of utilities (potential benefits) for what a consumer is willing to pay the agreed price that satisfies both the consumer and the producer, finishing with the fee-based service itself and its set of utilities provided by the producer for the consumer.

The product as the market supply form is traditional for our markets. Its supply by a producer with the subsequent use of its utilities (potential benefits) by a consumer in its value chains (Porter's value chains) is considered to be its characteristic feature. modernized products - traditional products supplemented with the utilities and properties that make them more attractive for the traditional markets of the organization; modified products - traditional products supplemented with the utilities and properties that make them attractive for the additional markets (market segments). In addition to the typical goods forms - item (product), it is also necessary to refer to this market supply form such as the spare parts and consumables supplied to the market to ensure the use of the item

*Corresponding author lelya.babenko.90@mail.ru 
(product) by the consumer. Less popular in our markets is such a form of the product as adapters, extending the traditional and new products scope of use. And even less popular in our markets is the form of products - modernizing kits that provide the traditional products consumers with the items that are more attractive and useful.

\section{Materials and methods}

The utility $\Omega \mathrm{j}$ of the marketable output will be evaluated by the consumer according to the wide range of its potential benefits, of which the predominant ones are: - potential functional benefit - $\omega \mathrm{j} \mathrm{k}$, based on its additional functionalities of the product being introduced to the market; - resource (cost, price) potential benefit - $\omega \mathrm{j} 1$, which provides the cost reduction while using a product with utility $\Omega \mathrm{j}$; - potential adaptive benefit - $\omega \mathrm{j} \mathrm{m}$, which allows to adopt a new product to the consumer technological lines in a better way. Since the potential benefits $\omega \mathrm{j} \mathrm{k}, \omega \mathrm{j} 1, \omega \mathrm{j} \mathrm{m}$ of the marketable product can be realized in different ways, we assume that the utility $\Omega \mathrm{j}$ is estimated by the consumer according to its potential benefits conjunction $\omega \mathrm{j} \mathrm{k}, \omega \mathrm{j} 1, \omega \mathrm{j} \mathrm{m}$.

$$
\Omega_{j}=\omega_{j k} \cup \omega_{j l} \cup \omega_{j m}
$$

To estimate the degree to which the utility $\Omega \mathrm{j}$ is realized in a certain market i-product, ( $i \in I,, I-a$ list of goods circulating in the market under study), we introduce the notion of "strength" of utility. The "strength" $\varepsilon_{\mathrm{ji}}$ of j-utility for the market $\mathrm{i}$-supply will be calculated as the ratio of the realized utility in the market $i$-product to the realization maximum available in the market for this $\Omega \mathrm{j}$ utility.

In accordance with (1), the "strength" of j-utility in the market $\mathrm{i}$-offer will be the ratio conjunction of : - functional indicators $\mathrm{K}_{\mathrm{ji}}$ of $\mathrm{j}$-utility to the superior - $\operatorname{Supi}\left(\mathrm{K}_{\mathrm{j}}\right)$ functional indicator of $\mathrm{j}$-utility of the market offers circulating in the market under study; - indicators of the consumption resources $\varepsilon_{\mathrm{ji}}$ (value of the implementation costs, for example) Lji jutility to the inferior - Infi $(\mathrm{Lj})$ profitability indicators of the products traded in the market; adaptability indicators of $\mathrm{Mji}$ j-utility to the to the superior - $\operatorname{Supi}\left(\mathrm{M}_{\mathrm{j}}\right)$ adaptability indicator of the products circulating in the market.

$$
\varepsilon_{j i}=\frac{K_{j i}}{\operatorname{Sup}_{i}\left(K_{j}\right)} \cup \frac{L_{j i}}{\ln f_{i}\left(L_{j}\right)} \cup \frac{M_{j i}}{\operatorname{Sup}_{i}\left(M_{j}\right)}
$$

To calculate the attractiveness for the consumer - $\mu \mathrm{j}$ j-utility, we multiply the sales volume qji of each i-product possessing $\mathrm{j}$-utility by its utility "strength" cji and refer it to the sales volume Qi of the market under study. And the sum of these market offers indicators I we normalize to $\Sigma \mathrm{I} \mu \mathrm{j}$.

$$
\mu j=\frac{\Sigma_{I J} \frac{\varepsilon j i q j i}{Q i}}{\Sigma_{J} \mu j}
$$

$\widehat{\mu \mathrm{j}}$ - unnormalized attractiveness value $\mu J=\Sigma_{I J} \frac{\text { gji qji }}{Q i}$

The sum of all the attractiveness indicators $\mu \mathrm{j}$ is equal to $1(\Sigma \mathrm{J} \mu \mathrm{j}=1)$. 
The measure $\mu \mathrm{i}$ of the attractiveness of the market $\mathrm{i}$-offer for the market under study is its utility attractiveness conjunction.

$$
\mu_{i}=\mu_{i 1} \cup \mu_{i 2} \cup \ldots \cup \mu_{i j}
$$

Thus, functional, resource (cost), adaptive and all the rest utilities become a common integral indicator - attractiveness. It allows to rank any forms of the market offer for the market under study, from each of its participants (operators).

But, to formalize the portfolio policy, of the whole set I of the market offers circulating at the market under study $\left(\mu_{\mathrm{i}}>0, \forall \mathrm{i} \in \mathrm{I}\right)$ we will designate «our products» $\mu \mathrm{T}$, modernized traditional products attractiveness $-\mu \mathrm{TR}$.

we will designate «our products» $\mu \mathrm{T}$, modernized traditional products attractiveness $\mu \mathrm{TR}$.

To figure out the marketable output timing we estimate the dominance reserve $\Delta \mu \mathrm{T}$ and the speed $V \mu$ of the product attractiveness decrease. If the condition of the market dominance $\mu^{\mathrm{T}} \geq \mu_{\mathrm{i}} \mid \forall \mathrm{i} \in \mathrm{I}$, , the estimate of the dominance reserve $\Delta \mu \mathrm{T}$ will be

$$
\Delta \mu^{T}=\min \left(\mu^{T}-\mu_{i}\right) \mid \forall i \in I
$$

The product attractiveness decrease speed $\mathrm{V} \mu$ is

$$
V_{\mu}=\frac{\Delta \mu_{0}^{T}-\Delta \mu_{t}^{T}}{t}
$$

Where $\Delta \mu_{0}^{\mathrm{T}}$ and $\Delta \mu_{t}^{\mathrm{T}}$ respectively, the product attractiveness dominance reserve value when it is introduced to the market (index 0 ) and after the observation period (index $t$ ).

To estimate the remaining time of the item (product) market segment dominance we calculate the ratio of the reserve value $\Delta \mu \mathrm{T}$ to the attractiveness decrease value $V \mu$

$$
\mathrm{t}^{\text {house }}=\frac{\Delta \mu \mathrm{T}}{\mathrm{V} \mu} \text {. }
$$

The estimate of the remaining time of the item (product) market segment dominance allows to make the informed decisions about the preparation timing for the current item (product) modernization, about necessary resources and its allocation intensity.

However, for the successful preparation of the current (regular) item (product) modernization, it is necessary to determine the goals of its conduct [8]. It is known that the possibilities of the current (regular) modernization are determined while designing the product.

While the specification of the current (regular) modernization goals is determined by the prevailing market conditions, the entry of the competitors' products into the market, changes in the reaction of the potential buyers on the functional indicators utility $\mathrm{K}$, on the resource consumption indicators utility $\mathrm{L}$ and the adaptability indicators utility $\mathrm{M}$.

Tentatively, the modernization goal with respect to the utility indicators $\mathrm{K}, \mathrm{L}, \mathrm{M}$ can be determined by the relations similar to (3), (5), (6), (7).

Attractiveness for the consumer of the K- utility $-\mu \mathrm{K}$ will be

$$
\mu K=\frac{\sum_{I K} \frac{\varepsilon_{K i} q_{K i}}{Q i}}{\Sigma_{K} \mu K}
$$


$\widehat{\mu_{\mathrm{K}}}$ - unnormalized attractiveness value

$$
\mu K=\Sigma_{I K} \frac{\varepsilon_{K i} q_{K i}}{Q i}
$$

The sum of all the attractiveness indicators $\mu \mathrm{K}$ is equal to $1(\Sigma \mathrm{K} \mu \mathrm{K}=1)$.

The dominance reserve value $\Delta \mu_{K}^{T}$ will be:

$$
\Delta \mu_{K}^{T}=\min \left(\Delta \mu_{K}^{T}-\mu_{i K}\right) \mid \forall i \in I
$$

The speed $\mathrm{V} \mu \mathrm{K}$ of the product attractiveness decrease will be:

$$
V \mu_{K}=\frac{\Delta \mu_{K}^{T}-\Delta \mu^{T} K t}{t}
$$

Where $\Delta \mu_{\mathrm{K} 0}^{\mathrm{T}}$ and $\Delta \mu_{\mathrm{Kt}}^{\mathrm{T}}$ respectively, the product functional attractiveness dominance reserve value when it is introduced to the market (index 0 ) and after the observation period $\mathrm{t}$ (index $\mathrm{t}$ ).

To estimate the remaining time $t_{\mathrm{K}}^{\text {house }}$ of the item (product) market segment functional attractiveness dominance we calculate the ratio of the reserve value $\Delta \mu_{\mathrm{K}}^{\mathrm{T}}$ to the speed of the attractiveness $\mathrm{K}$-decrease value $\mathrm{V}_{\mu \mathrm{K}}$

$$
\mathrm{t}_{\mathrm{K}}^{\text {house }}=\frac{\Delta \mu_{\mathrm{K}}^{\mathrm{T}}}{\mathrm{V} \mu \mathrm{K}},
$$

The attractiveness of the L-utility for the consumer will be:

$$
\mu_{L}=\frac{\sum_{I L} \frac{\xi_{L i q_{L i}}}{Q_{i}}}{\sum_{L} \mu L}
$$

$\widehat{\mu_{\mathrm{L}}}$ - unnormalized attractiveness resource value $\mu_{L}=\sum_{I L} \frac{\xi_{L i q_{L i}}}{Q_{i}}$

The sum of all the attractiveness indicators $\mu \mathrm{L}$ is equal to $1(\Sigma \mathrm{L} \mu \mathrm{L}=1)$.

The dominance reserve value $\Delta \mu_{\mathrm{L}}^{\mathrm{T}}$ will be:

$$
\Delta \mu_{K}^{T}=\min \left(\Delta \mu_{L}^{T}-\mu_{i L}\right) \mid \forall i \in I
$$

The speed $\mathrm{V} \mu \mathrm{L}$ of the product attractiveness decrease $\mathrm{L}$ will be:

$$
V \mu_{K}=\frac{\Delta \mu_{L 0}^{T}-\Delta \mu^{T} L t}{t}
$$

Where $\Delta \mu_{\mathrm{L} 0}^{\mathrm{T}}$ and $\Delta \mu_{\mathrm{Lt}}^{\mathrm{T}}$ respectively, the product resourceful attractiveness dominance reserve value $\mathrm{L}$ when it is introduced to the market (index 0 ) and after the observation period $\mathrm{t}$ (index $\mathrm{t}$ ). 
To estimate the remaining time $\mathrm{t}_{\mathrm{L}}^{\text {house }}$ of the item (product) market segment resourceful attractiveness dominance we calculate the ratio of the $L 0$.

reserve value $\Delta$ to the speed of the attractiveness L- decrease value $V_{\mu L}$.

$$
\mathrm{t}_{\mathrm{L}}^{\text {house }}=\frac{\Delta \mu_{\mathrm{L}}^{\mathrm{T}}}{\mathrm{V} \mu \mathrm{L}}
$$

The attractiveness of the M-utility for the consumer will be:

$$
\mu_{M}=\frac{\sum_{I M} \frac{\xi_{M i} g_{M i}}{Q i}}{\sum_{M} \mu M}
$$

$\widehat{\mu_{\mathrm{M}}}$ - unnormalized adaptative attractiveness value $\mu_{M}=\sum_{I M} \frac{\xi_{M i} g_{M i}}{Q i}$ the sum of all the attractiveness indicators $\mu \mathrm{M}$ is equal to $1(\Sigma \mathrm{M} \mu \mathrm{M}=1)$.

dominance reserve value $\Delta \mu_{\mathrm{M}}^{\mathrm{T}}$ will be:

$$
\Delta \mu_{M}^{T}=\min \left(\Delta \mu_{M}^{T}-\mu_{i M}\right) \mid \forall i \in I
$$

The speed $\mathrm{V} \mu \mathrm{M}$ of the product attractiveness decrease $\mathrm{M}$ will be:

$$
V \mu_{K}=\frac{\Delta \mu_{M 0}^{T}-\Delta \mu_{M t}^{T}}{t}
$$

Where $\Delta \mu_{\mathrm{M} 0}^{\mathrm{T}}$ and $\Delta \mu_{\mathrm{Mt}}^{\mathrm{T}}$ respectively, the product adaptive attractiveness dominance reserve $M$ value when it is introduced to the market (index 0 ) and after the observation period $\mathrm{t}$ (index $\mathrm{t})$.

To estimate the remaining time of the item (product) market segment resourceful attractiveness dominance we calculate the ratio of the $\mu_{M}^{T}$.

reserve value $\Delta$ to the speed of the attractiveness $M$-decrease value $V_{\mu \mathrm{M}}$.

While choosing the goal of the modernization, we choose the utility (K, L, M) which time dominance is the shortest.

\section{Conclusion}

The foregoing tool for the forecasting the timing and direction of the item (product) modernization does not in any way exclude a creative approach to it, it only helps to determine its timing and its resources allocation intensity, to make a justified choice over its direction.

\section{References}

1. A.D. Chistyakov, N.D. Eletsky, Advances in intelligent systems and computing 1095, 604-612 (2020) https://elibrary.ru/item.asp?id=41409413 
2. A.N. Beskopylny, V.B. Rykov, E.M. Zubrilina, A.D. Chistyakov, MATEC Web of Conferences, 04034 (2018) https://www.elibrary.ru/item.asp?id=36800825

3. U.I. Ermolev, A.D. Chistyakov, V.I. Pahomov, A.V Butovchenko, The Agricultural machinery and enterprises project bases (DSTU publishing center, Rostov-on-Don, 2016)

4. Yu. Zaitsev, Organizational and economic principles of marketing systems of agricultural enterprises in target product markets. Problems and prospects of economics and management, 115-122 (2016)

5. A. Eletxigerra, J.M. Barrutia, C. Echebarria, Journal of Destination Marketing \& Management, 72-84 (2018) https://doi.org/10.1016/j.jdmm.2017.11.002

6. F. Quoquab, J. Mohammad, Procedia Economics and Finance 37, 234-238 (2016) https://doi.org/10.1016/S2212-5671(16)30119-8

7. N.D. Line, R.C. Runyan, Tourism Management 43, 91-102 (2014) https://doi.org/10.1016/j.tourman.2014.01.024

8. M. Wright, D. Russell, Australasian Marketing Journal (AMJ) 20(3), 218-223 (2012) https://doi.org/10.1016/j.ausmj.2012.02.002

9. A.D. Chistyakov, The market offer variety increase as the mechanism for the innovative development of the regional economy. Pre-factors and mechanisms for the innovative development of the regional economy (Rostov-on-Don, SSC RAS, 2008)

10. S. Deng, C.A. Yano, Management Science 52(5), 741-756 (2006)

11. J.G. Kim, U. Menzefricke, F.M. Feinberg, Management Science 53(2), 340-354 (2007)

12. A.V. Prasolov, Russian management magazine 7(3), 45-60 (2009)

13. D.J. Hansen, J.H. Deacon, V. Pascal, Z. Sethna, Journal of Business Research (2019) https://doi.org/10.1016/j.jbusres.2019.05.030

14. D. Galliano, A. Gonçalves, P. Triboulet, Journal of Rural Studies 72, 273-285 (2019) https://doi.org/10.1016/j.jrurstud.2019.10.009

15. I.G. Akperov, The Regional Marketing Geospace Information System, 12-20 (2019) 